\title{
Geographic Distribution of Cryptic Species of Plasmopara viticola Causing Downy Mildew on Wild and Cultivated Grape in Eastern North America
}

\author{
Mélanie Rouxel, Pere Mestre, Anton Baudoin, Odile Carisse, Laurent Delière, Michael A. Ellis, David Gadoury, \\ Jiang Lu, Mizuho Nita, Sylvie Richard-Cervera, Annemiek Schilder, Alice Wise, and François Delmotte
}

First, fifth, tenth, and thirteenth authors: INRA, ISVV, UMR1065 Santé et Agroécologie du Vignoble, F-33883, Villenave d'Ornon, France; second author: INRA, UMR1131 Santé de la Vigne et Qualité du Vin, F-68000, Colmar, France; third author: Virginia Tech, Department of Plant Pathology, Physiology, and Weed Science, 417 Price Hall, Blacksburg 24061; fourth author: Agriculture and Agri-Food Canada, 430 Gouin Boulevard, Saint-Jean-sur-Richelieu, Quebec J3B 3E6, Canada; sixth author: Ohio State University, Department of Plant Pathology, 224 Selby Hall, Wooster; seventh author: Cornell University, Plant Pathology and Plant-Microbe Biology, 115 Barton Laboratory, NYSAES, Geneva, NY; eighth author: Florida Agricultural and Mechanical University, Center for Viticultural Sciences and Small Fruit, Tallahassee 32307; ninth author: Virginia Tech, Department of Plant Pathology, Physiology, and Weed Science, 595 Laurel Grove Road, Winchester 22602; eleventh author: Department of Plant Pathology, Michigan State University, East Lansing 48824; and twelfth author: Cornell University, Long Island Horticultural Research \& Extension Center, 3059 Sound Avenue, Riverhead, NY 11901. Accepted for publication 17 January 2014.

\begin{abstract}
Rouxel, M., Mestre, P., Baudoin, A., Carisse, O., Delière, L., Ellis, M. A., Gadoury, D., Lu, J., Nita, M., Richard-Cervera, S., Schilder, A., Wise, A., and Delmotte, F. 2014. Geographic distribution of cryptic species of Plasmopara viticola causing downy mildew on wild and cultivated grape in eastern North America. Phytopathology 104:692-701.

The putative center of origin of Plasmopara viticola, the causal agent of grape downy mildew, is eastern North America, where it has been described on several members of the family Vitaceae (e.g., Vitis spp., Parthenocissus spp., and Ampelopsis spp.). We have completed the first large-scale sampling of $P$. viticola isolates across a range of wild and cultivated host species distributed throughout the above region. Sequencing results of four partial genes indicated the presence of a new $P$. viticola

America is identical to Plasmopara muralis in Europe. The geographic distribution and host range of five pathogen species was determined through analysis of the internal transcribed spacer polymorphism of 896 isolates of $P$. viticola. Among three $P$. viticola species found on cultivated grape, one was restricted to Vitis interspecific hybrids within the northern part of eastern North America. A second species was recovered from $V$. vinifera and V. labrusca, and was distributed across most of the sampled region. A third species, although less abundant, was distributed across a larger geographical range, including the southern part of eastern North America. P. viticola clade aestivalis predominated (83\% of isolates) in vineyards of the European winegrape $V$. vinifera within the sampled area, indicating that a single pathogen species may represent the primary threat to the European host species within eastern North America.
\end{abstract} species on Vitis vulpina in Virginia, adding to the four cryptic species of $P$. viticola recently recorded. The phylogenetic analysis also indicated that the P. viticola species found on Parthenocissus quinquefolia in North

Additional keywords: plant pathogen.

The European winegrape species Vitis vinifera is cultivated worldwide. Grapevine downy mildew is considered one of the most important grapevine diseases in temperate climates. Plasmopara viticola (Berk. \& M. A. Curtis) Berl. \& De Toni, the causal agent of downy mildew, is a heterothallic oomycete endemic to eastern North America, where it has been described on many members of the family Vitaceae (1), including Vitis vinifera (European wine grape), V. labrusca L. (fox grape), V. riparia Michx. (riverbank grape), V. aestivalis Michx. (summer grape), $V$. cinerea (graybark grape), and $V$. vulpina (frost grape), as well as Parthenocissus quinquefolia L. Planch (Virginia creeper).

Plasmopara viticola was accidentally introduced into Europe in the 1870s with the importation of American wild Vitis spp. and phylloxera-resistant hybrids (29). In the last decade, several

Corresponding author: F. Delmotte; E-mail address: delmotte@bordeaux.inra.fr

* The $\boldsymbol{e}$-Xtra logo stands for "electronic extra" and indicates that the online version contains one supplementary table. Figures 1 to 5 appear in color online.

http://dx.doi.org/10.1094/PHYTO-08-13-0225-R

(C) 2014 The American Phytopathological Society population genetics studies have been carried out in Europe to assess the genetic diversity of $P$. viticola using microsatellite markers $(1,8-12,21,22)$. Most of these studies were conducted on a small spatial scale (i.e., within vineyards) and indicated that $P$. viticola populations were mainly panmictic, although footprints of clonal propagation were also found in some cases (8). Recently, Fontaine et al. (5) reported a genetic signature indicative of range expansion and a leap-frog event during the introduction and spread of $P$. viticola in Europe: a significant continent-wide population structure, with two geographically and genetically distinct clusters of $P$. viticola in western and eastern European vineyards.

Comparatively little information has been published regarding the genetic structure of $P$. viticola populations within its native range (eastern North America). North American populations of $P$. viticola were reported to be much more diverse than European populations, suggesting the existence of a founder effect at the introduction of this pathogen in Europe (21). A phylogenetic study on 14 isolates of $P$. viticola reported significant diversity among North American $P$. viticola isolates, suggesting the possibility of species boundaries in P. viticola (24). To assess cryptic speciation in $P$. viticola, Rouxel et al. (20) combined 
genetic, morphological, and virulence data on a large set of American $P$. viticola isolates and provided evidence that $P$. viticola is, in fact, a complex of four cryptic species, each with a unique degree of pathogenic specialization within the family Vitaceae. The study also indicated that two cryptic $P$. viticola species exhibited complete host plant specialization toward Parthenocissus quinquefolia and $V$. riparia, whereas two other cryptic species discovered on $V$. aestivalis, V. labrusca, and $V$. vinifera could infect a wider range of hosts in controlled experiments. Although the taxa evidenced by Rouxel et al. (20) should represent distinct species according to their genetic distances and their host ranges, the cryptic species were described as different formae speciales of Plasmopara viticola. This is because the pathogen species cannot be named until we examine the type specimen of $P$. viticola to determine the species to which the epithet viticola should be applied. In addition, a formal species description requires a thorough morphological investigation. For purposes of clarity, we employ a provisional nomenclature of $P$. viticola species and use the term clade in place of forma specialis.

More generally, these results on $P$. viticola confirm the finding that many plant diseases formerly believed to be caused by a single species are indeed associated with a complex of multiple cryptic species (3), such as Septoria tritici blotch of wheat. For $P$. viticola, ecological divergence through host adaptation is probably favored by its biotrophic lifestyle (6), a hypothesis that is supported by the growing number of genetic studies reporting cryptic speciation in biotrophic plant pathogens such as powdery and downy mildews $(6,16,17,23,26,27)$. The discovery of sibling species causing grapevine downy mildew naturally raises questions about their epidemiological implications. A better understanding of the spatial-temporal distribution of pathogen species may have important implications for disease management in vineyards. Investigating the association of $P$. viticola species with wild and cultivated hosts will also provide critical information for grapevine breeding, because this often involves interspecific hybridization and introgression of resistance from distantly related members of the host family. Rouxel et al. (20) provided valuable information on the level of specialization of $P$. viticola species; however, sampling was limited to the Great Lakes region of the United States, and did not include all the potential host species of P. viticola.

The present study represents the first large-scale sampling of $P$. viticola isolates across a range of wild and cultivated host species distributed throughout the putative center of origin of the pathogen: eastern North America. Here, we first used multiplegene genealogies to describe the phylogenetic relationships of the phylogenetic $P$. viticola species identified across the sampling. We then developed and used a rapid diagnostic tool based on internal transcribed spacer (ITS) polymorphism to infer the geographical range and the degree of pathogenic specialization within $P$. viticola across wild grape and cultivated vineyards.

\section{MATERIALS AND METHODS}

P. viticola sampling. Between 2007 and 2010, a large-scale survey of $P$. viticola was conducted on cultivated ( $V$. labrusca, $V$. vinifera, and interspecific hybrids) and wild (V. aestivalis, V. vulpina, V. cinerea, V. riparia, and Parthenocissus quinquefolia) (Fig. 1) grapevines in Canada (Québec) and in the United States (Florida, Michigan, North Carolina, New York, Ohio, Pennsylvania, Virginia, and West Virginia). In total, 890 isolates from 89 geographical sites on 5 wild Vitis spp. and 54 cultivated varieties were sampled (Table 1; Fig. 2). The cultivated varieties included $24 \mathrm{~V}$. vinifera cultivars, $4 \mathrm{~V}$. labrusca cultivars, and 27 interspecific hybrids (Table 2). In addition, three isolates of Plasmopara muralis collected on Parthenocissus tricuspidata in Bordeaux were used to assess the genetic relatedness with Plas- mopara viticola clade quinquefolia described by Rouxel et al. (20) from North America isolates.

DNA extraction. Isolates correspond to sporulation present on $1 \mathrm{~cm}^{2}$ of grapevine leaf infected with downy mildew. Fragments obtained from infected leaves were lyophilized overnight, and the DNA of each isolate was extracted according to the standard method (cetyl-trimethyl-ammonium-bromide, phenol-chloroform), followed by precipitation with isopropanol, as explained by Delmotte et al. (4).

Determination of ITS1 sequence polymorphism. A subsample of 254 isolates, corresponding to one to three isolates per host plant for each sampling site, was used for further sequencing of ITS1 (Table 1). Polymerase chain reaction (PCR) was performed using primers ITS1-O (CGGAAGGATCATTACC) and ITS2 (GCTGCGTTCTTCATCGATGC), as described by Rouxel et al. (20). Sequencing of PCR amplicons was outsourced to the Genomic and Sequencing Center of Bordeaux (Pierroton, France).

Cleaved amplified polymorphism sequence. In order to design a rapid diagnostic tool for inferring $P$. viticola species on a large number of isolates, we used the described single-nucleotide polymorphisms of the ITS1 and $\beta$-tubulin genes (20) to develop cleaved amplified polymorphic sequence (CAPS) markers. Four restriction enzymes (AseI, XmnI, TfiI, and HpyCH4V) were used that allow recognition of the different haplotypes of $P$. viticola. First, ITS1 PCR products were digested separately with three enzymes (AseI, XmnI, and TfiI) in parallel at the appropriate temperature in a final volume of $10 \mu \mathrm{l}$ containing $0.1 \mu \mathrm{l}$ of enzyme, $1 \mu \mathrm{l}$ of PCR product, $1 \times$ buffer, and $0.1 \mu \mathrm{l}$ of bovine serum albumen when necessary (XmnI digestion). Restriction fragments were visualized on $2 \%$ agarose gels. Altogether, this allowed us to distinguish four restriction profiles corresponding to five $P$. viticola species (Table 2). In order to discriminate the species that have the same ITS1 restriction profile, the $\beta$-tubulin PCR products were digested with $\mathrm{HpyCH} 4 \mathrm{~V}$ using the same conditions as described for the other enzymes (Table 3 ).

Sequencing, alignments, and phylogenetic inference. In order to reconstruct the phylogenetic relationships among $P$. viticola species, 19 isolates of $P$. viticola, including the five $P$. viticola species and 3 isolates of $P$. muralis, were sequenced on four genomic regions: ITS1 and fragments of actin (act), $\beta$-tubulin $(t u b)$, and cytochrome b (cytb) (Supplementary Table 1). PCR amplifications were performed using primers and PCR conditions described by Rouxel et al. (20) for ITS1, act, and tub genes and by Chen et al. (2) and Giresse et al. (7) for the cyt $b$ gene.

Sequences of the four partial genes were aligned using Muscle implemented in Seaview (14). The best-fit models of nucleotide substitution were selected using MODELTEST v. 3.06 (18) based on likelihood scores for 88 different models and the Akaike information criterion. Phylogenetic relationships among isolates were inferred using maximum likelihood methods implemented in PhyML (15). Genealogies were constructed using the heuristic search function, with 1,000 random addition replicates, and tree bisection and reconstruction using a branch-swapping algorithm. Gaps were treated as unknown characters. To estimate branch support, bootstrap values were determined using 1,000 bootstrap replicates.

A species tree inference approach was used to establish the relationship among the lineages identified. We estimated the species tree of $P$. viticola using Bayesian methods under the *BEAST v1.7.3 software package (15). A Yule speciation process was specified because it is the most appropriate when comparing relationships between species. We ran Monte Carlo Markov chains for 10 million generations, sampling trees every 1,000 generations and using a strict molecular clock. We used Tracer v1.5 (Rambaut and Drummond [19]) to assess likelihood stabilization and convergence for BEAST analyses, and discarded the first $10 \%$ of trees as burn-in. 


\section{RESULTS}

ITS1 polymorphism. The ITS1 region (238 bp) presents 16 polymorphic sites determining five haplotypes. Among the 254 isolates sequenced for ITS1, 247 presented one of the four haplotypes described by Rouxel et al. (20) that correspond each to a cryptic species of $P$. viticola (Tables 1 and 2). A new haplotype was found for seven isolates collected on V. vulpina in Virginia, revealing the detection of a new species of $P$. viticola in North America.

Species inference by CAPS. The 254 isolates sequenced for ITS1 were used to validate the detection of grapevine downy mildew species by the CAPS method (Table 3). Results obtained by CAPS of ITS1 and $\beta$-tubulin and ITS1 sequencing were
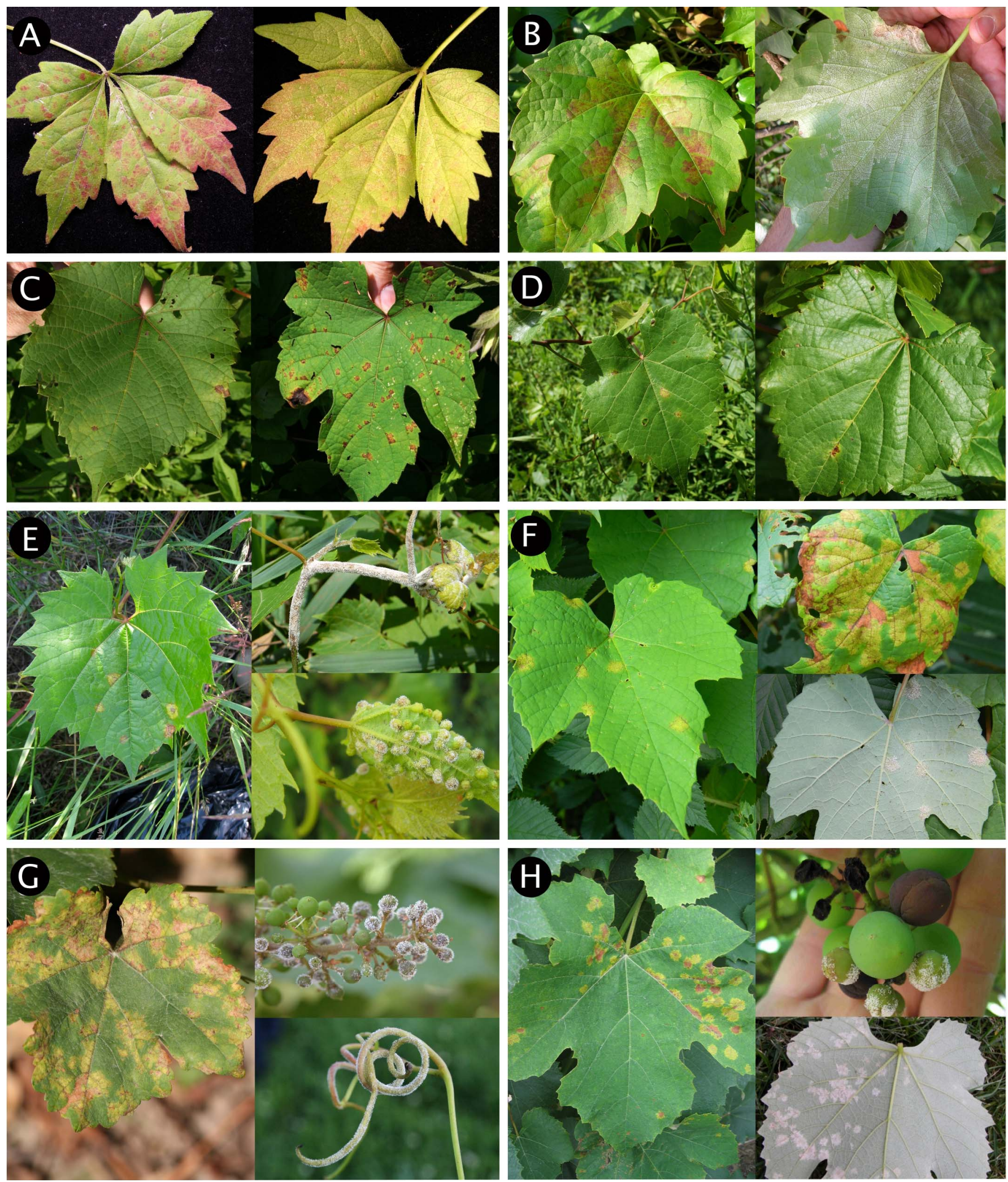

Fig. 1. Wild and cultivated Vitis spp. infected with grapevine downy mildew: A, Parthenocissus quinquefolia $; \mathbf{B}$, P. tricuspidata; C, Vitis cinerea $; \mathbf{D}$, V. vulpina $; \mathbf{E}$, V. riparia $; \mathbf{F}$, V. aestivalis; $\mathbf{G}$, V. vinifera; and $\mathbf{H}$, V. labrusca. 
entirely congruent. Amplification of the ITS1 region and $\beta$-tubulin was successfully obtained for 764 of 890 isolates analyzed. CAPS analysis allowed us to infer 290 isolates to $P$. viticola clade riparia, 304 isolates to $P$. viticola clade aestivalis, 126 isolates to $P$. viticola clade vinifera, 37 isolates to $P$. viticola clade quinquefolia, and 7 isolates to $P$. viticola clade vulpina (Table 2).
Distribution of $\boldsymbol{P}$. viticola species. The geographical range of the different $P$. viticola species on their host plants is presented in Figure 3 and Table 3. P. viticola clade riparia was restricted to Canada and the Great Lakes region, where it was present on a unique wild species, $V$. riparia. We found that this species can also infect many cultivated interspecific hybrids in Canada,

TABLE 1. Number of samples of downy mildew collected on wild and cultivated grapevine

\begin{tabular}{|c|c|c|c|c|c|c|c|c|c|c|}
\hline \multirow[b]{2}{*}{ Samples } & \multicolumn{10}{|c|}{ Sampling area (sequenced isolates) ${ }^{\mathrm{z}}$} \\
\hline & Canada & Michigan & Ohio & $\begin{array}{l}\text { New } \\
\text { York }\end{array}$ & Pennsylvania & $\begin{array}{c}\text { West } \\
\text { Virginia }\end{array}$ & Virginia & $\begin{array}{c}\text { North } \\
\text { Carolina }\end{array}$ & Florida & Total \\
\hline Number of locations & 20 & 16 & 3 & 19 & 2 & 5 & 16 & 5 & 3 & 89 \\
\hline \multicolumn{11}{|l|}{ Wild species } \\
\hline Parthenocissus quinquefolia & 0 & $38(2)$ & 0 & $6(0)$ & 0 & 0 & 0 & 0 & 0 & $44(2)$ \\
\hline Vitis aestivalis & 0 & $22(2)$ & $8(5)$ & 0 & $11(2)$ & $18(9)$ & $16(3)$ & 0 & $10(1)$ & $85(22)$ \\
\hline$V$. cinerea & 0 & 0 & 0 & 0 & 0 & $7(5)$ & 0 & 0 & 0 & $7(5)$ \\
\hline V. riparia & 0 & $84(10)$ & $6(2)$ & $69(4)$ & 0 & 0 & 0 & 0 & 0 & $159(16)$ \\
\hline V. vulpina & 0 & 0 & 0 & 0 & $7(5)$ & $10(10)$ & $28(17)$ & 0 & 0 & $45(32)$ \\
\hline Total & 0 & $144(14)$ & $14(7)$ & $75(4)$ & $18(7)$ & $35(24)$ & $44(20)$ & 0 & $10(1)$ & $340(77)$ \\
\hline \multicolumn{11}{|l|}{ Cultivated species } \\
\hline$V$. vinifera & 0 & $64(10)$ & $10(2)$ & $46(11)$ & 0 & 0 & $42(12)$ & $26(8)$ & 0 & $188(43)$ \\
\hline V. labrusca & 0 & $48(7)$ & $10(4)$ & $16(4)$ & 0 & 0 & $13(2)$ & 0 & 0 & 87 (17) \\
\hline Interspecific hybrids & $114(79)$ & $93(21)$ & & $18(3)$ & 0 & 0 & $25(4)$ & 0 & $25(10)$ & 275 (117) \\
\hline Total & $114(79)$ & $205(38)$ & $20(6)$ & $80(18)$ & 0 & 0 & $80(18)$ & $26(8)$ & $25(10)$ & $550(177)$ \\
\hline Grand total & $\ldots$ & $\ldots$ & $\ldots$ & $\ldots$ & $\ldots$ & $\ldots$ & $\ldots$ & $\ldots$ & $\ldots$ & $890(254)$ \\
\hline
\end{tabular}

${ }^{\mathrm{z}}$ Number of isolates for which the internal transcribed spacer 1 region has been sequenced is indicated in parentheses.

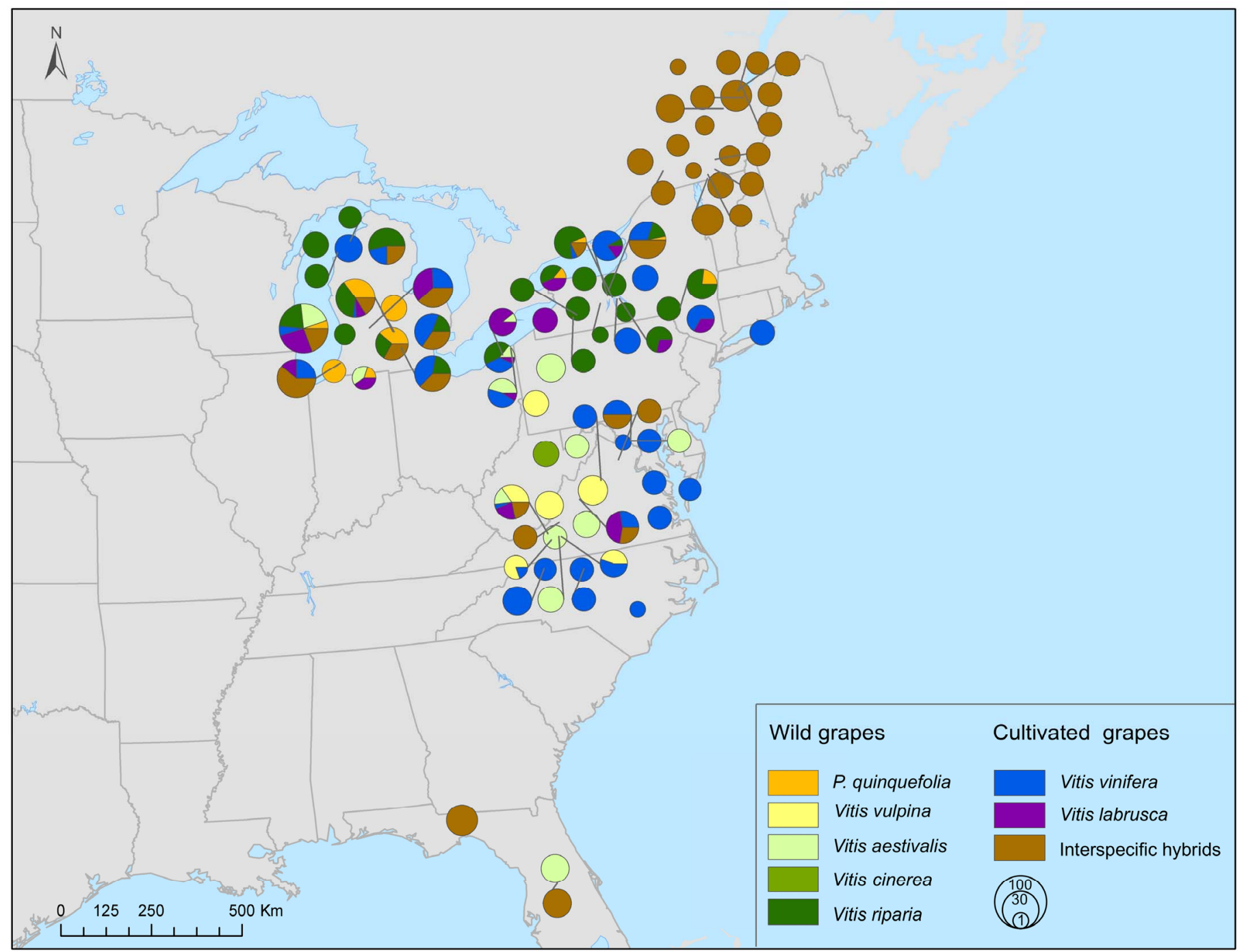

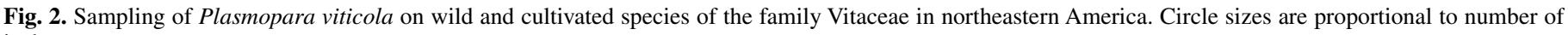
isolates. 
Michigan, and New York (Table 3). P. viticola clade aestivalis is widespread in the eastern United States, from Canada to North Carolina. This species was present on a single wild species, $V$. aestivalis. It was also abundant on V. vinifera, V. labrusca cultivars, and some interspecific hybrids (Table 3 ). P. viticola clade vinifera was widely distributed across northeastern America. It was the only species of grapevine downy mildew present in the southern United States (Florida). This species was present on three wild species (V. vulpina, V. cinerea, and $V$. aestivalis) but, for $V$. aestivalis, it was detected only in Florida. This species was also found on $V$. vinifera cultivars in Michigan and on cultivated interspecific hybrids having $V$. aestivalis genetic background in Florida. P. viticola clade quinquefolia was restricted to the northern United States on the wild species Parthenocissus

TABLE 2. Detailed information of the distribution of Plasmopara viticola species found on cultivated grape

\begin{tabular}{|c|c|c|c|c|}
\hline \multirow[b]{2}{*}{ Species, cultivar } & \multirow[b]{2}{*}{ Sampling locations $(n)^{\mathrm{y}}$} & \multicolumn{3}{|c|}{ Samples of $P$. viticola species $^{\mathrm{z}}$} \\
\hline & & Clade riparia & Clade aestivalis & Clade vinifera \\
\hline \multicolumn{5}{|l|}{ Vitis vinifera } \\
\hline Aglianico & Virginia (1) & 0 & 4 & 0 \\
\hline Cabernet Franc & New York (3), North Carolina (1), Virginia (1) & 0 & 9 & 0 \\
\hline Cabernet Sauvignon & North Carolina (2), Ohio (1), Virginia (1) & 0 & 5 & 0 \\
\hline Chambourcin & Virginia (1) & 0 & 2 & 0 \\
\hline Chardonnay & Michigan (4), New York (3), North Carolina (3), Virginia (5) & 0 & 46 & 6 \\
\hline Frankentahaler & New York $(1)$ & 0 & 1 & 0 \\
\hline Frontenac & Michigan (1) & 0 & 0 & 1 \\
\hline Gamay & Michigan (1) & 0 & 0 & 1 \\
\hline Gewurtztraminer & Michigan (1), New York (1) & 0 & 1 & 5 \\
\hline Lakemond & New York (1), Virginia (1) & 0 & 9 & 0 \\
\hline Merlot & New York (1), North Carolina (1) & 0 & 5 & 0 \\
\hline Muscat & Ohio (1) & 0 & 4 & 0 \\
\hline Nebbiolo & North Carolina (1) & 0 & 1 & 0 \\
\hline Petit Verdot & North Carolina (1), Virginia (1) & 0 & 2 & 0 \\
\hline Pinot noir & Michigan (3), New York (1) & 0 & 9 & 6 \\
\hline Pinotage & New York (1) & 0 & 1 & 0 \\
\hline Riesling & Michigan (2), New York (3), Ohio (1) & 0 & 8 & 11 \\
\hline Sangiovese & New York (1), North Carolina (2), Virginia (1) & 0 & 5 & 0 \\
\hline Syrah & Michigan (1) & 0 & 0 & 4 \\
\hline Tannat & North Carolina (1), Virginia (2) & 0 & 8 & 0 \\
\hline Traminette & Michigan (1), North Carolina (1) & 0 & 2 & 3 \\
\hline Unknown & Michigan (3), Virginia (1) & 0 & 4 & 3 \\
\hline Viognier & North Carolina (1) & 0 & 1 & 0 \\
\hline Riesling & New York (1) & 0 & 0 & 4 \\
\hline Total & $\ldots$ & 0 & 127 & 44 \\
\hline \multicolumn{5}{|l|}{ V. labrusca } \\
\hline Catawba & New York (1) & 0 & 2 & 0 \\
\hline Concord & Michigan (4), New York (4), Ohio (3), Virginia (1) & 0 & 29 & 0 \\
\hline Fredonia & New York (1) & 0 & 1 & 0 \\
\hline Niagara & Michigan (3) & 0 & 0 & 38 \\
\hline Total & $\ldots$ & 0 & 32 & 38 \\
\hline \multicolumn{5}{|l|}{ Interspecific hybrids } \\
\hline Mars & Michigan (1) & 2 & 3 & 0 \\
\hline Blanc du bois & Florida (2) & 0 & 0 & 11 \\
\hline Chancellor & Canada (1), Michigan (4), New York (1) & 37 & 0 & 0 \\
\hline Chardonel & Michigan (1) & 0 & 3 & 0 \\
\hline Cliche & Canada (3) & 10 & 1 & 0 \\
\hline E-4-7 & Canada (1) & 1 & 1 & 0 \\
\hline Freedom & New York (1) & 0 & 1 & 0 \\
\hline Hybrid 30-5-1 & Florida (1) & 0 & 0 & 4 \\
\hline Hybrid 30-7-1 & Florida (1) & 0 & 0 & 3 \\
\hline Lake Emerald & Florida (1) & 0 & 0 & 4 \\
\hline Landol & Michigan (1) & 0 & 0 & 1 \\
\hline Lucie Kuhlmann & Canada (1) & 7 & 0 & 0 \\
\hline Marechal Foch & Canada (3) & 8 & 2 & 0 \\
\hline Marquis & Michigan (3) & 0 & 7 & 4 \\
\hline Muscat de Swenson & Canada (1) & 4 & 0 & 0 \\
\hline NY-73.136 & Michigan (1) & 0 & 0 & 2 \\
\hline Ortega & Michigan (1) & 2 & 0 & 0 \\
\hline Rkatsiteli & Michigan (1) & 4 & 0 & 0 \\
\hline Sainte Croix & Canada (4) & 11 & 7 & 0 \\
\hline Seyval blanc & Canada (1) & 0 & 2 & 0 \\
\hline Seyval noir & Canada (1) & 0 & 1 & 0 \\
\hline Stover & Florida (1) & 0 & 0 & 3 \\
\hline Table grape & Michigan (1) & 0 & 4 & 0 \\
\hline Unknown & Canada (1), Michigan (2) & 1 & 0 & 6 \\
\hline Vandal-Cliche & Canada (6) & 29 & 1 & 0 \\
\hline Vidal & Canada (2), Michigan (1), Virginia (3) & 10 & 15 & 5 \\
\hline Vignoles & Michigan (3), New York (1) & 18 & 3 & 0 \\
\hline Total & $\ldots$ & 144 & 51 & 43 \\
\hline Grand total & $\ldots$ & 144 & 210 & 125 \\
\hline
\end{tabular}

y Number of locations per region $(n)$.

z Total number of samples showing positive results is indicated for each $P$. viticola species. 
quinquefolia. Plasmopara viticola clade vulpina has been found on V. vulpina at Blacksburg and Pilot (Virginia).

Phylogenetic analyses. Sequences for ITS1, tub, and act were obtained from $19 P$. viticola and three P. muralis isolates. Gene $c y t b$ was sequenced for $13 P$. viticola isolates but it could not be amplified from $P$. muralis isolates and $P$. viticola clade quinquefolia isolates. Among the 22 isolates analyzed, we obtained five haplotypes for ITS1, 16 for $a c t, 18$ for $t u b$, and 11 for $c y t b$. Variable sites identified in coding regions resulted only from synonymous substitutions, except for $c y t b$, which presented 14 nonsynonymous substitutions. Globally, the most polymorphic region was cytb (nucleotide diversity [pi] $=0.05209$ ) and the least polymorphic was ITS1 (pi $=0.02255)$. The numbers of parsimony informative sites (excluding gaps) were 15, 47, 75, and 93 for $I T S 1, a c t, t u b$, and $c y t b$, respectively.

MODELTEST indicated that the best model for the data was the General Time Reversible model for each of the four gene regions. The phylogenies obtained from the sequence data of the gene regions were first determined separately. Individual phylogenetic trees (ITS1, act, tub, and cytb) supported five monophyletic groups of isolates delimiting five $P$. viticola species (Fig. 4). Individual trees were congruent (i.e., for each gene tree, the five monophyletic lineages supported included the same isolates). The reconstruction of the phylogenetic relationships among the five downy mildew species were well resolved by $t u b$ whereas ITS1, act, and cytb individual trees did not resolve the among taxa relationships. The species tree obtained with $*$ BEAST indicated that $P$. viticola clade vulpina is closely related to $P$. viticola clade aestivalis (Fig. 5).

\section{DISCUSSION}

Rouxel et al. (20) previously described that $P$. viticola includes four independent evolutionary lineages corresponding to different host-specialized cryptic species. Using the phylogenetic concordance of multiple unlinked genes (25), this study discriminates five cryptic species of $P$. viticola in eastern North America. The sampling of a larger geographical area and host plant diversity allowed the detection of a new phylogenetic lineage on $V$. vulpina, hereafter named $P$. viticola clade vulpina, evolving without gene flow and showing significant genetic divergence from the already described $P$. viticola species. This species is represented by seven isolates that have been found on $V$. vulpina at Blacksburg and Pilot, VA. More samples of $P$. viticola clade vulpina together with virulence results from cross-pathogenicity tests would be necessary before conclusions can be drawn about the specialization of this species on $V$. vulpina. It is worth noting that our data already indicate that another species of $P$. viticola (clade vinifera) is able to infect $V$. vulpina. Altogether, our data confirm that grapevine downy mildew is caused by a complex of at least five cryptic species that have radiated on the Vitaceae family.
A recent phylogenetic and morphological study indicates that outbreaks of downy mildew on Parthenocissus tricuspidata are caused by a new species described as Plasmopara muralis (28). Our data reveal that $P$. viticola species specialized on Virginia creeper (Parthenocissus quinquefolia) in North America (20) is identical to the one found on Japanese ivy ( $P$. tricuspidata) in Europe (28). The genus Parthenocissus contains different species grown for ornamental use worldwide; some originated in North America, such as P. quinquefolia, others in Asia, such as $P$. tricuspidata. Therefore, several scenarios could explain the current distribution of the downy mildew species on this genus: in one of them, the pathogen is native to North America, where it infects $P$. quinquefolia and is invasive in Europe on P. tricuspidata; alternatively, an undetected species of downy mildew present in Asia on Parthenocissus spp. has spread on P. tricuspidata in Europe and on $P$. quinquefolia in North America. It is worth noting that different varieties of Plasmopara viticola have been described on endemic Asian Vitis spp. (13). However, in the absence of clear-cut distinguishing features, these taxa are not widely recognized and remain to be confirmed by molecular phylogenetic investigations. Whatever the scenario, it remains to be explained why the species has not been described yet on Parthenocissus quinquefolia in Europe and $P$. tricuspidata in America. However, it is possible that the mild symptoms caused by Plasmopara spp. on Parthenocissus spp. have led to the pathogen being overlooked on these species.

Beyond the identification of these species of Plasmopara viticola, this study brings new insights into the geographical and host plant ranges of the five $P$. viticola species that are now described. In the north- and central-eastern United States, several grapevine downy mildew species coexist at different spatial scales (i.e., within a plant and at the vineyard scale). The same individual host plant can be infected by two different $P$. viticola species, as seen for 'Marechal Foch' at Saint Hilaire and Knowlton in Canada or for the table grape 'Marquis' at Benton-Harbor, MI. We have also found several $P$. viticola species coexisting at the vineyard scale: in Fennville, MI, a $P$. viticola species infected $V$. riparia, a second species infected $V$. aestivalis and $V$. vinifera, and a third one was found on Parthenocissus quinquefolia.

In contrast to the northeast, only one species was detected on grapevines in Florida (Plasmopara viticola clade vinifera). Compared with other $P$. viticola species that are confined to a restricted area, this species is, indeed, the most widely distributed geographically in North America, present from Canada to Florida. However, one should not lose sight of the fact that the geographical range of grapevine downy mildew species is strongly dependent on the host range of the pathogen and host plant distribution. The wide host range of $P$. viticola clade vinifera, with hosts widely distributed, may therefore explain why it has been able to spread over the whole of eastern North America.

The present study confirms previous results on the host range of grapevine downy mildew species (20) and describes their

TABLE 3. Cleaved amplified polymorphic sequence description for the deduction of Plasmopara viticola species (clades) based on the restriction profiles of internal transcribed spacer (ITS) 1 and tubulin sequences

\begin{tabular}{|c|c|c|c|c|c|c|c|c|c|c|c|c|c|c|c|c|c|c|}
\hline \multirow[b]{3}{*}{ Clade } & \multirow[b]{3}{*}{ Accession $^{v}$} & \multirow{2}{*}{\multicolumn{13}{|c|}{ ITS1 polymorphic sites }} & \multicolumn{4}{|c|}{ Restriction profile } \\
\hline & & & & & & & & & & & & & & & \multicolumn{3}{|c|}{ ITS1 } & \multirow{2}{*}{$\frac{\beta \text {-Tubulin }}{\mathrm{HpyCH} \mathrm{V}^{\mathrm{z}}}$} \\
\hline & & 2 & 25 & 37 & 38 & 53 & 56 & 70 & 75 & 93 & 94 & 102 & 172 & 173 & TfiI $^{\mathrm{w}}$ & Ase $^{\mathrm{x}}$ & $\mathrm{XmnI}{ }^{\mathrm{y}}$ & \\
\hline riparia & JF897779 & $\mathrm{T}$ & A & $\mathrm{T}$ & A & $\mathrm{C}$ & $\mathrm{T}$ & $\mathrm{T}$ & $\mathrm{C}$ & $\mathrm{C}$ & $\mathrm{T}$ & $\mathrm{T}$ & $\mathrm{T}$ & $\mathrm{G}$ & a1 & a1 & a1 & $\ldots$ \\
\hline aestivalis & JF897780 & $\mathrm{T}$ & A & $\mathrm{C}$ & $\mathrm{T}$ & $\mathrm{T}$ & $\mathrm{C}$ & $\mathrm{G}$ & $\mathrm{C}$ & $\mathrm{T}$ & $\mathrm{T}$ & $\mathrm{T}$ & $\mathrm{C}$ & $\mathrm{G}$ & a1 & a1 & $\mathrm{a} 2$ & b1 \\
\hline vinifera & JF897781 & A & $\mathrm{C}$ & $\mathrm{C}$ & $\mathrm{T}$ & $\mathrm{T}$ & $\mathrm{C}$ & $\mathrm{T}$ & $\mathrm{C}$ & $\mathrm{C}$ & A & A & $\mathrm{C}$ & G & a1 & $\mathrm{a} 2$ & $\mathrm{a} 2$ & $\ldots$ \\
\hline quinquefolia & JF897782 & $\mathrm{T}$ & $\mathrm{C}$ & $\mathrm{C}$ & $\mathrm{T}$ & $\mathrm{T}$ & $\mathrm{C}$ & $\mathrm{T}$ & $\mathrm{T}$ & $\mathrm{T}$ & $\mathrm{T}$ & $\mathrm{T}$ & $\mathrm{C}$ & G & a2 & a1 & a2 & $\ldots$ \\
\hline vulpina & KF652198 & $\mathrm{T}$ & $\mathrm{A}$ & $\mathrm{C}$ & $\mathrm{T}$ & $\mathrm{T}$ & $\mathrm{C}$ & $\mathrm{T}$ & $\mathrm{C}$ & $\mathrm{T}$ & $\mathrm{T}$ & $\mathrm{T}$ & $\mathrm{C}$ & A & a1 & a1 & $\mathrm{a} 2$ & $\mathrm{~b} 2$ \\
\hline
\end{tabular}

v ITS1 GenBank accession.

${ }^{\mathrm{w}}$ Digestion fragments sizes: $\mathrm{a} 1=71,169 ; \mathrm{a} 2=240$.

${ }^{x}$ Digestion fragments sizes: $\mathrm{a} 1=240 ; \mathrm{a} 2=100,140$.

y Digestion fragments sizes: $\mathrm{a} 1=101,139 ; \mathrm{a} 2=66,73,101$.

${ }^{\mathrm{z}}$ Digestion fragments sizes: $\mathrm{b} 1=75,215,229$; $\mathrm{b} 2=75,101,103,229$. 

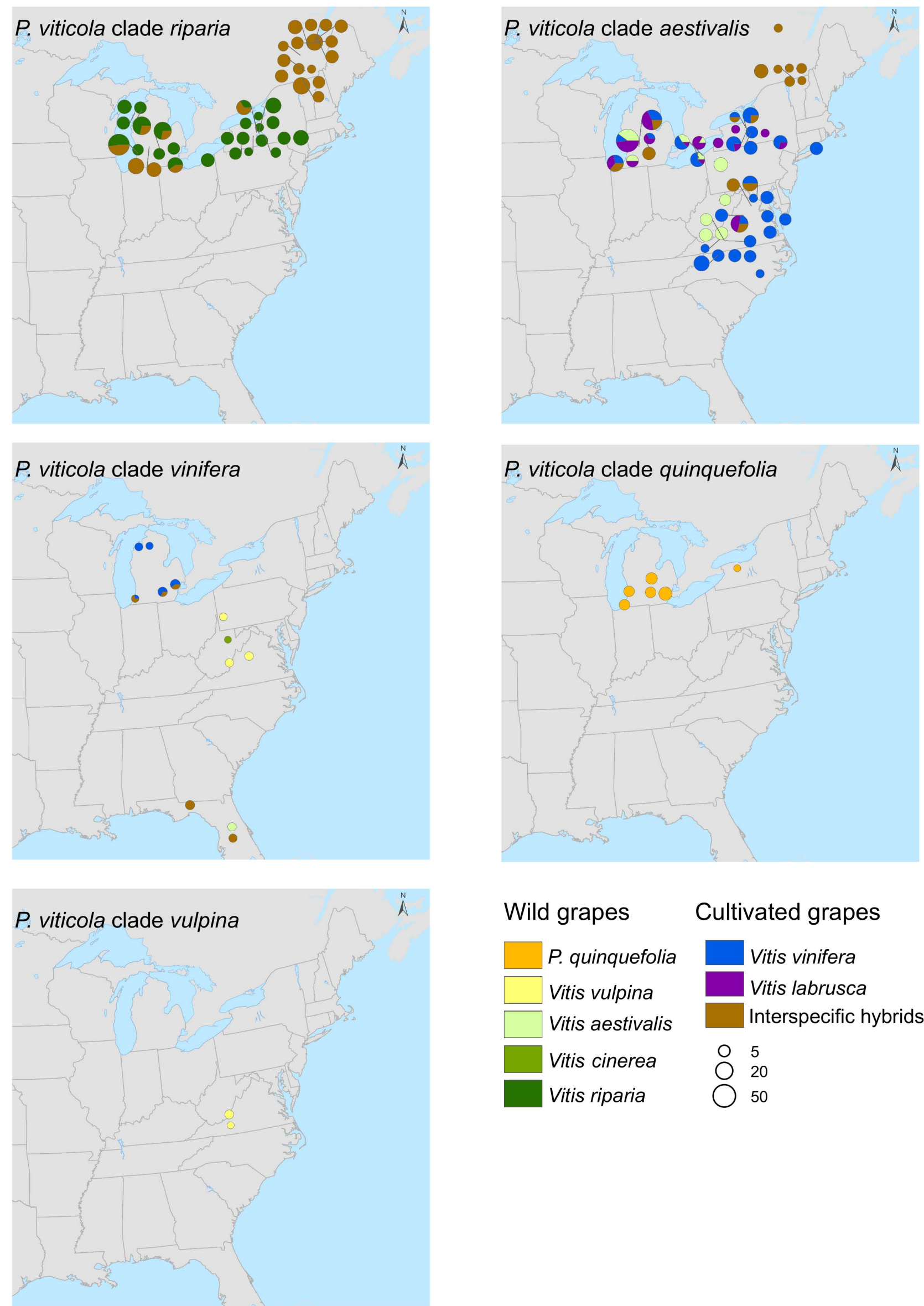

Wild grapes Cultivated grapes

\begin{tabular}{|c|c|}
\hline P. quinquefolia & Vitis vinifera \\
\hline Vitis vulpina & Vitis labrusca \\
\hline Vitis aestivalis & Interspecific hybrids \\
\hline Vitis cinerea & $\begin{array}{l}5 \\
20\end{array}$ \\
\hline Vitis riparia & 50 \\
\hline
\end{tabular}

Fig. 3. Geographical range of the Plasmopara viticola species on their host-plants in northeastern North America. Circle sizes are proportional to number of isolates. 
distribution on wild and cultivated grapevines at a larger geographical scale. We found a complete host plant specialization of the pathogen toward Parthenocissus quinquefolia and V. riparia, whereas Plasmopara viticola species found on $V$. aestivalis, $V$. cinerea, $V$. vulpina, $V$. labrusca, and $V$. vinifera exhibited a comparatively broader host range. Three different species of $P$. viticola were found to attack cultivated grapevines: the first one ( $P$. viticola clade riparia) is only able to infect interspecific hybrids such as 'Chancellor', Marechal Foch, 'Vandal-Cliché', and 'Vignoles'. The second one (P. viticola clade vinifera) was found on $V$. vinifera cultivars and on hybrids. The third one $(P$. viticola clade aestivalis) has the widest host range, being able to infect $V$. vinifera cultivars, V. labrusca cultivars, and hybrids. It is worth noting that, although $V$. vinifera is susceptible to two $P$. viticola species, most of the $V$. vinifera vineyards $(83 \%)$ were specifically attacked by $P$. viticola clade aestivalis. Therefore, this downy mildew species is likely to be the most important when the European (and therefore exotic in North America) species $V$. vinifera is planted into the center of origin for P. viticola.

\section{ACKNOWLEDGMENTS}

Research was supported by the French National Research Agency (ANR-07-BDIV-003), the French Ministry for Agriculture and Fisheries (CTPS-C06-2008-vigne), and the Foundation Jean Poupelain (Javrezac, France).

\section{ITS1}
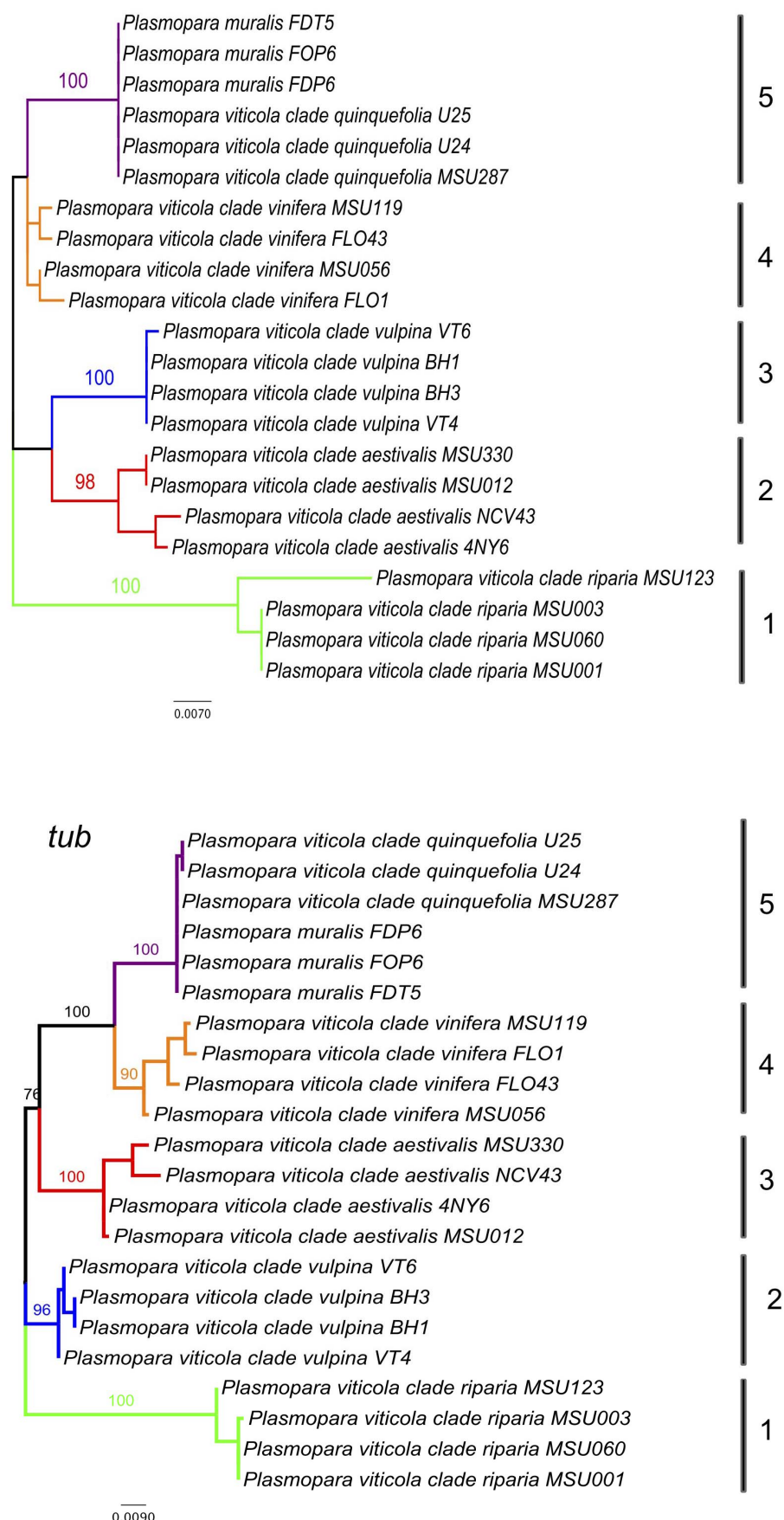

Fig. 4. Phylogenetic reconstruction maximum likelihood (ML) based on partial sequence data of internal transcribed spacer (ITS) 1 , actin (act), $\beta$-tubulin (tub), and cytochrome $\mathrm{b}(\mathrm{cytb})$. Numbers at branches indicate bootstrap support $>70 \%$ in ML analysis. 1: Plasmopara viticola clade riparia; 2 : $P$. viticola clade aestivalis; 3 : $P$. viticola clade vulpina; 4: $P$. viticola clade vinifera; 5: Plasmopara viticola clade quinquefolia and $P$. muralis. 


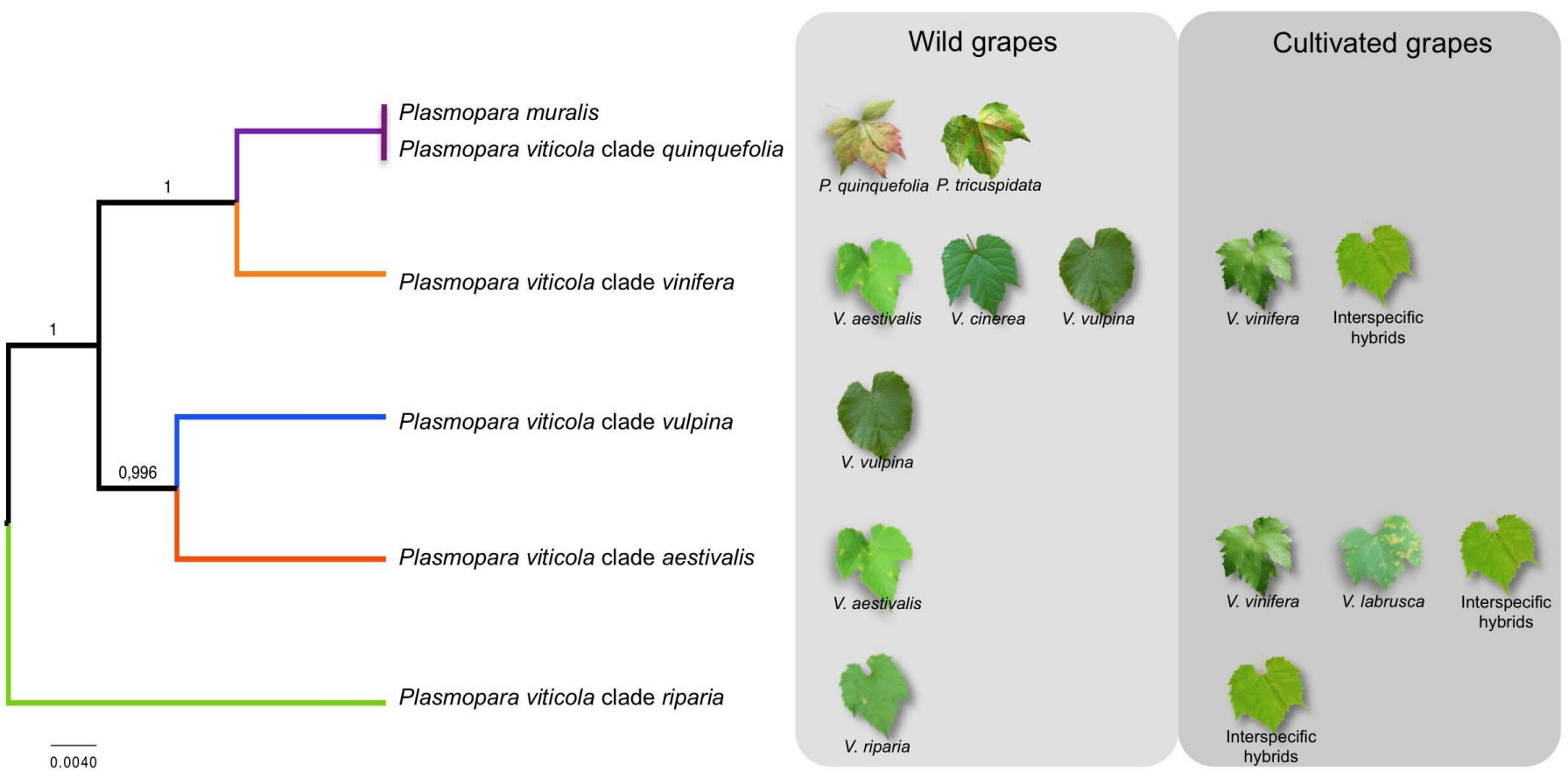

Fig. 5. Species tree of Plasmopara viticola species constructed using *BEAST based on the four partial sequences (internal transcribed spacer 1 , $\beta$-tubulin, actin, and cytochrome b) from P. viticola and P. muralis isolates. Posterior probabilities of the branches are given in the tree. Leaf pictures indicate the source host plants for each $P$. viticola clade.

\section{LITERATURE CITED}

1. Bush \& Son, and Meissner. 1883. Illustrated Descriptive Catalogue of American Grape Vines; A Grape Grower's Manual. R. P. Studley \& Co., St. Louis.

2. Chen, W. J., Delmotte, F., Richard-Cervera, S., Douence, L., Greif, C., and Corio-Costet, M. F. 2007. At least two origins of fungicide resistance in grapevine downy mildew populations. Appl. Environ. Microbiol. 73:5162-5172.

3. Crous, P. W., and Groenewald, J. Z. 2005. Hosts, species and genotypes: opinions versus data. Australas. Plant Pathol. 34:463-470.

4. Delmotte, F., Chen, W. J., Richard-Cervera, S., Greif, C., Papura, D., Giresse, X., Mondor-Genson, G., and Corio-Costet, M. F. 2006. Microsatellite DNA markers for Plasmopara viticola, the causal agent of downy mildew of grapes. Mol. Ecol. Notes 6:379-381.

5. Fontaine, M., Austerlitz, F. T., Giraud, T., Labbé, F., Papura, D., RichardCervera, S., and Delmotte, F. 2013. Genetic signature of a range expansion and leap-frog event after the recent invasion of Europe by the grapevine downy mildew pathogen Plasmopara viticola. Mol. Ecol. 22:2771-2786.

6. Giraud, T., Gladieux, P., and Gavrilets, S. 2010. Linking the emergence of fungal plant diseases with ecological speciation. Trends Ecol. Evol. 25:387-395.

7. Giresse, X., Ahmed, S., Richard-Cervera, S., and Delmotte, F. 2010. Development of new oomycete taxon-specific mitochondrial cytochrome $\mathrm{b}$ region primers for use in phylogenetic and phylogeographic studies. J. Phytopathol. 158:321-327.

8. Gobbin, D., Bleyer, G., Keil, S., Kassemeyer, H. H., and Gessler, C. 2007. Evidence for sporangial dispersal leading to a single infection event and a sudden high incidence of grapevine downy mildew. Plant Pathol. 56:843-847.

9. Gobbin, D., Jermini, M., Loskill, B., Pertot, I., Raynal, M., and Gessler, C. 2005. Importance of secondary inoculum of Plasmopara viticola to epidemics of grapevine downy mildew. Plant Pathol. 54:522-534.

10. Gobbin, D., Pertot, I., and Gessler, C. 2003. Identification of microsatellite markers for Plasmopara viticola and establishment of high throughput method for SSR analysis. Eur. J. Plant Pathol. 109:153164.

11. Gobbin, D., Pertot, I., and Gessler, C. 2003. Genetic structure of a Plasmopara viticola population in an isolated Italian mountain vineyard. J. Phytopathol. 151:636-646.

12. Gobbin, D., Rumbou, A., Linde, C. C., and Gessler, C. 2006. Population genetic structure of Plasmopara viticola after 125 years of colonization in European vineyards. Mol. Plant Pathol. 7:519-531.

13. Golovina, N. P. 1955. Sravnitelnaya karakteristika obrazov Plasmopara viticola Berl. et de Toni iz raznih stran. Botanicheskie materialy otdela sporovih rastenii, Botanicheskovo Instituta im. V. L. Komarova, izd. A. N. SSR 10:138-144.

14. Gouy, M., Guindon, S., and Gascuel, O. 2010. SeaView version 4: a multiplatform graphical user interface for sequence alignment and phylogenetic tree building. Mol. Biol. Evol. 27:221-224.

15. Guindon, S., and Gascuel, O. 2003. A simple, fast, and accurate algorithm to estimate large phylogenies by maximum likelihood. Syst. Biol. 52:696704

16. Kiss, L., Khosla, K., Jankovics, T., Niinomi, S., Braun, U., and Takamatsu, S. 2006. A morphologically ill-founded powdery mildew species, Pleochaeta indica, is recognized as a phylogenetic species based on the analysis of the nuclear ribosomal DNA sequences. Mycol. Res. 110:1301-1308.

17. Mougou, A., Dutech, C., and Desprez-Loustau, M. L. 2008. New insights into the identity and origin of the causal agent of oak powdery mildew in Europe. For. Pathol. 38:275-287.

18. Posada, D., and Crandall, K. A. 1998. MODELTEST: testing the model of DNA substitution. Bioinformatics 14:817-818.

19. Rambaut, A., and Drummond, A. J. 2007. Tracer v1.4: MCMC trace analyses tool. http://beast.bio.ed.ac.uk/Tracer

20. Rouxel, M., Mestre, P., Comont, G., Lehman, B. L., Schilder, A., and Delmotte, F. 2013. Phylogenetic and experimental evidence for hostspecialized cryptic species in a biotrophic oomycete. New Phytol. 197:251-263.

21. Rouxel, M., Papura, D., Nogueira, M., Machefer, V., Dezette, D., RichardCervera, S., Carrere, S., Mestre, P., and Delmotte, F. 2012. Microsatellite markers for characterization of native and introduced populations of Plasmopara viticola, the causal agent of grapevine downy mildew. Appl. Environ. Microbiol. 78:6337-6340.

22. Rumbou, A., and Gessler, C. 2006. Particular structure of Plasmopara viticola populations evolved under Greek island conditions. Phytopathology 96:501-509.

23. Runge, F., Choi, Y.-J., and Thines, M. 2012. Phylogenetic investigations in the genus Pseudoperonospora reveal overlooked species and cryptic diversity in the P. cubensis species cluster. Eur. J. Plant Pathol. 129:135146.

24. Schroder, S., Telle, S., Nick, P., and Thines, M. 2011. Cryptic diversity of Plasmopara viticola (Oomycota, Peronosporaceae) in North America. Org. Div. Evol. 11:3-7.

25. Taylor, J. W., Jacobson, D. J., Kroken, S., Kasuga, T., Geiser, D. M., Hibbett, D. S., and Fisher, M. C. 2000. Phylogenetic species recognition and species concepts in fungi. Fungal Genet. Biol. 31:21-32.

26. Telle, S., Shivas, R. G., Ryley, M. J., and Thines, M. 2011. Molecular phylogenetic analysis of Peronosclerospora (Oomycetes) reveals cryptic 
species and genetically distinct species parasitic to maize. Eur. J. Plant Pathol. 130:521-528.

27. Thines, M., Runge, F., Telle, S., and Voglmayr, H. 2010. Phylogenetic investigations in the downy mildew genus Bremia reveal several distinct lineages and a species with a presumably exceptional wide host range. Eur. J. Plant Pathol. 128:81-89.
28. Thines, M., Runge, F., Telle, S., and Voglmayr, H. 2011. Recent outbreaks of downy mildew on grape ivy (Parthenocissus tricuspidata, Vitaceae) in Germany are caused by a new species of Plasmopara. Mycol. Progr. 10:415-422.

29. Viennot-Bourgin, G. 1949. Les champignons parasites des plantes cultivées. Masson \& Cie, Librairies de l'Académie de Médecine, Paris. 